\title{
Cognitive Phenomenology: the Promising Pragmatic Marriage of Methodologies in the Field of Theatre Studies?
}

Jan Motal

\section{Introduction}

The post-war transformation of the humanities paradigm, concerned with art and theatre, should be characterized as a shift to communication theory. As Philippe Breton shows in his convincing theory, this so-called communication utopia is based on the debiologization of conscience. Based on Norbert Wiener's mathematical vision of cybernetics, and on research on the principles of mass media, communication is connected with the perspective of control (BRETON 1997: 20). To understand communication means understanding the principles of social oppression, as shown in modern critical discourse analysis. ${ }^{1}$ To master communication is to master the tools of successful social engineering. Cybernetics was raised from new ontology, establishing new science. The new ontology grasps real within its relations to phenomena insofar as the very existence of phenomenon is defined by its relations (BRETON 1997: 25). The real is constituted by its reactions (feedback), and this behavioural vision of conscience is determined by the flow of inputs and outputs. The difference between information and conscience is confused, and knowledge is reduced to fact (BRETON 1997: 140). Experience as a basis for knowledge is abandoned, and the concept of 'human' is deprived of its biological and environmental context. This debiologization enables sign to become a major tool for the analysis of what is now widely recognized as discursiveness in society, politics and art.

We can find the concept of an information system in the following fields: the study of art (in semiotics), in television studies (in the notion of code) (FISKE and HARTLEY 2003), and in poststructuralism (in the concept of discourse).

1 'What I want to suggest is that the sociolinguistic order is the domain of hegemonic struggle, and that one dimension of the struggle of a group to establish its hegemony over a domain or institution is a struggle for sociolinguistic hegemony.' (FAIRCLOUGH 1995: 247) 
The notions of discourse, or code, as enclosed systems of signs, reminds us of Husserl's critique of mathesis universalis. In his monograph, The Crisis of European Sciences and Transcendental Phenomenology, he revealed the modern occidental science as the manifestation of a Leibnizian universal mathematical scientific utopia. He opposes scientifically reducing phenomena to the formal net of definitions and relations (Ideenkleid) (HUSSERL 1976: 45-8). The scientist 'dresses' phenomena in the clothes of ideas, and covers their nature with scientific technique. This approach leads us to the concept of phénoménotechnique - revealing the constructive nature of science. As Bachelard points out in his philosophy of science, Le nouvel esprit scientifique, scientists construct phenomena by designing their structure and choosing their essential components (BACHELARD 1968: 147-8).

But Husserl observes something more important. He exposes the specific demands of modern science. Science aspires to provide an exhaustive system of description, and explanation of reality, based on a mathematical structure. This mathesis universalis grasps the entire world in its ideality and promotes the vision of fact and relation as the essence of knowledge.

Cybernetics did not bring anything new to science; it merely reinforced the deep-set tendencies of modern science. And semiotics, with its system of signs and codes, and communication studies with its conception of information flow and discourse analysis (with its linguistic basis), are likewise logocentric. They originate in the vision of mathematical order - logos, defined by its informational structure. As Breton remarks: Jacquese Lacan, Claude Levi-Strauss and Jean-François Lyotard are all participating in the same sacralization of information (BRETON 2011: 66). According to Breton, the entire fields of postmodern philosophy and posthumanism suffer from the reduction of conscience, confusing knowledge and information.

Concerning art, artists and audiences, scholars seem to be obsessed with messages - '[...] often messages of a stridently political cast', as Noël Carroll remarks (2000: 191). Conceptual art, with its anti-aesthetic antagonism, has been the symbol of "postmodern' effort for more than a generation. I am much more willing to accept it as the expression of the communication paradigm, which is profoundly modern in its rational logocentrism. For art historians the notion of post-modernism should be plausible. There are many artists who use the notion to describe their artistic identity. But from a philosophical viewpoint, the concept - that art constructs or deconstructs mythology or ideology via information delivery - is unsound. The question is: is there a bright methodological future for theatre studies? I think so. We are now witnessing a new cognitive pivot. Does it bring new hope for theatre studies and is it ready to lead us out of the cave of logocentrism? Not necessarily. But there is ground for a nourishing shift in the paradigm, which I call cognitive phenomenology. The crucial assertion of my contribution is that the inoculation of cognitive sciences with phenomenological hermeneutics produces a better understanding of the arts, and especially theatre. 


\section{Towards the Cognitive Turn}

In the early to mid-20 $0^{\text {th }}$ century, psychology was predominantly oriented towards the issues of impulses within the individual, below the level of consciousness (i.e. psychodynamical theories, e.g. psychoanalysis). Theories were also concerned with external influences on human responsiveness (behaviour theory). During the 1970s, scholars became interested in grouping cognition, behaviour and environment together, as the complex reciprocal determinants of each other (BANDURA 1977: 2-13).

The emergence of cognitivism (i.e. the understanding of human behaviour in the terms of how people think) is rooted not only in the field of psychology, but also in post-war communication studies and computation research (STERNBERG 2009: 11). It was Ulric Neisser's seminal book, Cognitive Psychology, which deeply influenced the so-called cognitive revolution in the 1960s. ${ }^{2}$ In his approach, Neisser also referred to the terms of information science. Information is transformed into cognition (memory in this case), '[...] and the structured pattern of its transformation is what we want to understand' (NEISSER 2014: 8). The so-called program analogy was based on a conviction that the mind is a type of software program and the body is its respective hardware. ${ }^{3}$

Later, psychologists uncovered limitations to this approach (its epistemological obstacles were mentioned earlier). After the long domination of: mind grasped as an abstract information processor, a change of paradigm emerged, bringing in a complex new perspective: '[...] human cognition, rather than being centralized, abstract, and sharply distinct from peripheral input and output models, may instead have deep roots in sensomotoric processing.' (WILSON 2002: 625) The so-called embodied cognitio ${ }^{4}$ is the withdrawal of communication epistemology. The revolutionized cognitive science now understands cognition as situated (in the context of a real-world environment), time pressured (in an interaction with the environment) and for action. Humans also off-load cognitive work onto environment, which is therefore a part of the cognitive system. Off-line cognition is body based (its function is to guide action) (WILSON 2002: 626).

This new approach wholly impugns the communication theory paradigm. There is no such thing as pure information, and formal symbolic structures (sign, signifier and signified) are not sufficient for a complete understanding of cognitive processes. It is reminiscent of Thomas Aquinas and his concept of human. According to him, intellect is in the form of the body. The human understands their Lebenswelt (living world) because the mind is embodied, not detached ('[...] intellectus [...] sit humani corporis forma.'; AQUINAS 1880: 13 [I, q. 76, art. 1]). The human soul is not material and it is not possible to detach it from the body (speaking about the mundane human life). This doctrine is rooted in Aristotle's De anima teleology and presents a pre-modern perspective which is possible to interpret in non-dualistic terms.

2 I.e. the 'first-generation cognitive science' or 'traditional cognitive science'.

3 Notably Neisser advocated an ecological approach engaging experiments in environment, avoiding an artificial setting of laboratory.

4 I.e. 'second-generation cognitive science'. 
As shown, the communication paradigm extends Cartesian dualism: res cogitans engages formal symbolic relations. From the aforementioned perspective of Aquinas: it is impossible to reduce human action only to the symbolic relation. The soul is embodied. Correspondingly, the mind is embodied and situated according to the perspective of cognitive science. We can conclude that there is a possibility to recover pre-modern and pre-Cartesian philosophical concepts according to the cognitive paradigm of embodiment. This discovery is going to be useful when discussing Aristotle's Poetics.

\section{The Amalgamated Mind}

Mark Rowlands provides an in-depth analysis of the cognitive science concepts in his seminal work, The New Science of the Mind. He concludes that 'the mind', as a term in science, is indefensible. Scholars can define no borders of the mind, thus so-called mental processes are not located entirely in the human brain. Rowlands also opposes the 'program analogy', arguing mental processes can hardly be described purely in the terms of representation transformations (ROWLANDS 2010: 51). The cognitive processes are hybrid and involve both internal and external operations, meaning that there is no isolated Cartesian mind and body, but a continuous system of brain, body and environment; in which the body is situated: 'Cognitive processes are an amalgam of neural structures and processes, bodily structures and processes, and environmental structures and processes. We can subsume the theses of the embodied mind and the extended mind into one: the amalgamated mind.' (ROWLANDS 2010: 83) Rowlands rejects the notions of embedded and enacted mind, as used in cognitive science, arguing they are neo-Cartesian in their perspective of human being ' [...] as a biological entity within biological boundaries of the usual sort' (ROWLANDS 2010: 76).

Knowledge is not only the acquisition of information, but also complex practical wisdom. To gain knowledge, a human needs to gain an insight into the knowledge issue, and also contract an environmentally embedded habit: 'The bodily dispositions I have acquired in the course of learning to surf themselves have to be tailored to specific environmental contingencies. For example, the ability to surf on a 7'11' Mini-mal does not translate into the ability to surf on a 5'11' Thruster.' (ROWLANDS 2010: 79)

Mark Rowlands' approach emphasizes the scientific perspective. But it is possible to interpret his theory from a philosophical vantage point. There are two important aspects of the amalgamated mind concerning art, that I will elaborate on. The first is its connection to the notion of practical wisdom, the second are its existential implications.

\section{Practical Wisdom and Its Meaning for Theatre}

According to Aristotle, the human soul is divided into: speculative intellect and practical intellect. The latter includes art competence (techne) and practical wisdom (phronesis). As Linda Zagzebski remarks, 'These virtues are directed toward the contingent, the 
former to pertaining to things to be made, the latter to pertaining to things to be done' (ZAGZEBSKI 1996: 213). Aristotle defines phronesis in Book VI of his Nicomachean Ethics. He states: '[...] a prudence is necessarily a characteristic accompanied by reason, in possession of the truth, and bound up with action pertaining to the human goods' (ARISTOTLE 2011: 121 [1140b20]).

Practical wisdom has the character of acquired habit and its acquirement could be compared to a cithara player learning to play (ARISTOTLE 2011: 13 [1098a10]). The habituation of practical wisdom is a bodily learning process, of which the goal is to be a good person. That process is analogous to the goal of the cithara player (to be a good musician). This is the telos (end) of practical human effort: goodness and happiness. He, who knows how to play cithara properly, knows theory and has acquired appropriate skills. So, both reason and practical faculties are involved in the acquisition of wisdom. The notion of phronimos has the meaning of a person who can regulate their behaviour. Practical wisdom is socially based and is acquired through social experience (ZAGZEBSKI 1996: 228). We act towards others and see our faults and lapses, we also see others acting, and we can distinguish the effects of their agency and imitate them.

This character of phronesis is in accordance with Bandura's social learning theory, emphasizing ' $[\ldots]$ the prominent roles played by vicarious, symbolic, and self-regulatory processes in psychological functioning' (BANDURA 1977: vii). A better understanding of how physical experience (emotions, bodily social agency) is transformed into theoretical knowledge, is at the heart of practical wisdom. Especially with the help of cognitive science and the notion of the amalgamated mind. As I have shown, Rowlands' environmentally embedded habit is the end of the learning process (e.g. learning to surf or learning to play a cithara according to Aristotle). This process is not located in the bounded mind, but lies in the continuum of brain, body and environment. The possibility of dissolving the mind into the continuous system gives us the advantage of understanding learning. Not only as a pure intellectual issue, but also as a complex, environmentally and bodily dependent mental process. Nevertheless, we should not leave aside the fact that Aristotle defines practical wisdom within the framework of deliberative choice (FINNIGAN 2014).

An attentive reader of the Philosopher should note that even the teleology of Aristotle's theory of art is unavoidably practical. The analysis of tragedy in Poetics gives us the clear notion of art ethics. As Richard Janko argues, '[t]he mimesis of the hamartia arouses the appropriate emotion to the proper degree: its catharsis enables us to moderate our own tendency to err in life in respect of that emotion' (JANKO 1992: 352). Our perception of drama can improve our moral competence and boost our practical wisdom. And not only in the case of tragedy - as Janko claims in the aforementioned article, comedy has its practical telos as well. The cognitive notion of amalgamated mind is valuable as a useful tool for the better understanding of the psychology of practical wisdom, especially in its connection to art and drama. We can hardly overestimate its helpfulness in future experimental research of Aristotle's concepts. Thanks to the field of cognitive science, such research is now plausible. As seen earlier, pre-modern philosophical concepts (such as Aristotle's or Aquinas') could be successfully interpreted in terms of the embodied mind. 


\section{The Rise of Mind from Existentiality}

Mark Rowlands presents the concept of human being without clear biological boundaries. But his argument hardly implies the same concept for the existential situation of human. From the scientific perspective it is adequate to see a human being as a continuum, but in the existential sense there is always me and you, and a deep discontinuity between me and world. Let me discuss the issue more closely.

The amalgamated mind transforms to an individual mind possessing boundaries through the process of self-awareness. ${ }^{5}$ As Fichte shows in his argument, The Foundations of Natural Right, '[...] the rational being cannot posit itself as a rational being with the self-consciousness without positing itself as an individual, as one among several rational beings that it assumes to exist outside itself.' (FICHTE 2000: 9) In his commentary, Frederick Neuhouser remarks that Fichte's notion of 'rational' means a self-positing or self-determining subject (within the context of practical philosophy involving the practical wisdom) (FICHTE 2000: xiii). The notion transcends the usual concept of self-awareness, because it engages the awareness of freedom. An individual is self-conscious not only in recognition of an identity of diverse psychological states, but also through the emergence of will (my term, in Fichte's perspective it is a free agency). So the subject acquires its boundaries through the recognition of freedom, determined by relations to others (society of other selves).

So it is the situation of self-awareness that gives the self the possibility to emerge. This situational power to shape an action is well known in social psychology (DELAMER and WARD 2013: 319-20) and it connects practical philosophy with psychology.

The particular moment of recognition of the self in a relation to others is also described in Hegel's philosophy of law. From a pure indefinite will, it is the act of the will that brings a constraint to the infiniteness of will. The German words, Da ('here' - situation) and Sein (v. 'to be' - original, undifferentiated Being) are compounded to coin the term Dasein - the individual (HEGEL 2013: 25). It is the act of distinction, providing a constraint to the undifferentiated Being, that a) produces an individual, and b) makes any recognition of the Being possible (self-awareness). This distinction, 'Unterscheidung', is the situation of individuality and its manifestation of interdependence of the self and the non-self (others). Through the decision-making, the will puts itself as the particular will of the individual (HEGEL 2013: 29).

For both Fichte and Hegel, the process is the source of law. The unavoidable recognition of self as constrained by others, and therefore free (as others are free) ${ }^{6}$, is the recognition of a community of free beings. This is the cornerstone of a right (Naturrecht; FICHTE 2000: 10).

5 The process in which 'I', or self, emerges. 'By "self" we commonly mean the particular being any person is, whatever it is about each of us that distinguishes you or me from others, draws the parts of our existence together, persists through changes, or opens the way to becoming who we might or should be.' (SIEGEL 2005: 3) The selfhood shapes both our personal and social existence. That is why I use the word boundaries in the notion of 'mind with boundaries' as the synonym of the self. So for the rest of this my text the notions of self and mind are interchangeable in the sense of phenomenality.

6 It means also the recognition of the self as a mirror of other selves (free agents). 
A right is fostered by '[...] a consciousness of oneself not as a discrete unit of casual efficacy but as being whose capacity for agency gives it a special dignity or value that makes it deserving of an exclusive sphere of activity that is respected by others' (FICHTE 2000: xvii). From the psychological point of view, it is remarkable that the human self emerges from intersubjectivity, meaning the self (' $\mathrm{I}$ ') is self-aware only when something else co-exists (external world, other free agents). Even in the conception of the self-aware mind which possesses boundaries, there is no subject/object isolation, but rather interdependence. And this self-awareness is connected with the recognition of dignity and value. Phenomenality is rooted in the capacity of individual judgment, and our consciousness is practical in its individuality.

Adopting the three-dimensional concept of selfhood by Jerrold Siegel (2005: 5-6) on the grounds of my previous argument, I can easily impugn Siegel's first dimension of physical, corporal self. As a biological entity, humans are more of a physical-environmental continuum, and from this perspective there is no distinctly delineated 'mind'. Physiologically (and evolutionary) oriented cognitive science has cannot prove the existence of mind, because the mind is amalgamated. But at the level of the relational (raises from social and cultural interaction) and reflective (self is an active agent of its own realization) dimensions of self we can evidently recognize the mind, which possess boundaries, thanks to its identity. The mind as the self is therefore clearly differentiated from others (world, other selves). The former dimension (relational) is the epistemological region of cognitive science, the latter (reflective) is the perspective of phenomenality and the locus of phenomenology as the science of phenomenality.

For instance, allow me to take the problem of free will as an example of the two-dimensionality ${ }^{7}$ of cognitive phenomenology. From the perspective of evolutionary psychology, it is necessary to submit that there is no such thing as free will. Free will is an illusion, as Daniel M. Wegner claims, in the sense that '[...] the experience of consciously willing an action is not a direct indication that the conscious thought has caused the action' (WEGNER 2002: 2). The conscious will is something that is experienced, but it is hardly the force of mind, asserts Wegner. Shifting our perspective, from the phenomenological perspective, free will is the crucial condition 'sine qua non' of individuality. If we are self-aware, we are free agents, as we have seen early in the heart of Fichte's deduction. There is a reciprocity between free will and the self, because it is only the self that can be free and there has to be the self for free agency. The so-called autonomy is phenomenal but as a physiological fact it is a type of illusion. There is no autonomy in a scientific determinism ex definitione, because determinism as such excludes any possibility of the autonomy. On the contrary, phenomenality is based on the intentionality of the self - there has to be the self to have an intentional relationship. And, of course, the self is defined right in relationship to the world. So the self is necessarily intersubjective (i.e. social).

There is no sense in pushing cognitive science to use the notion of free will in the phenomenological sense, and vice versa. Both perspectives are adequate and

7 I would prefer to use this notion instead of that of dualism, because it has nothing to do with the Cartesian dualism I am committed to avoid. This is not an ontological duality, but an epistemological one. 
complementary. But only one of the perspectives makes art (and theatrical artwork) possible - the phenomenality.

\section{Phenomenality of Meaning}

In his book, The Neural Imagination, Irving Massey presents a crucial argument for any discussion on the cognitive science of art. If art is framed as something meaningful, phenomenality is needed, as there is no meaning at the level of mere senses or cognition. There can be the structure of informational relations (like an objective 'dictionary', i.e. the relationship between a word and a reality) at the level of a formal symbolic code, but there could not be the meaning. 'It [the meaning] exists in a space of potentiality [...] We have to become conscious of our own words in order to decide if they mean anything', claims Massey (2009: 180). Computational machines can work with information; sort it, put it into formal relationships and make 'judgements' (of sorts) about it. But they do not understand it. It is the same with a neurological representation: the mere structure of neurons is 'dull'. It is humans who become aware of words and grasp them in understanding - that is, decide what they mean.

As John R. Searle insists: purely formal principles are not sufficient for understanding (SEARLE 1980: 418). The famous Turing test can be passed without the actual understanding of information used by a machine in its 'communication'. Searle's Gedankexperiment 'thought experiment' of the Chinese room, demonstrates that the notion of understanding is a mere metaphor or analogy in the case of formal symbolic systems (especially used by machines) (SEARLE 1980: 419). The meaning of information is a phenomenal issue and can only be constructed by self-aware consciousness - the self (mind). Massey applies this finding to the field of art: 'Works of art create meanings that are simply not contained in their elements but emerge for the first time from the collision of those elements' (MASSEY 2009: 181). But this collision of elements is operated by the mind, it is a phenomenal activity. For that reason, semiotics is interpretation. It is also why mere descriptive structuralism without interpretation is only the formal analysis of artwork, without a deeper understanding of its meaning. ${ }^{8}$

Art, including performance, is a complex aesthetic experience. Noël Carroll espouses, from a new perspective, what this fact means; as he is opposing the traditional Kantian aesthetics of disinterested attention. A spectator, reader or listener experiences both the form of artwork and its expression. Therefore, there can also (but not necessarily) be interpretative experiences (discerning the meaning of an artwork). Those are '[...] obviously connected to our ability to negotiate our common life with conspecifics whose intentions - overt and covert - we must be able to interpret' (CARROLL 2000: 199). The philosopher claims that there is no need for the concept of the aesthetic experience engaged in for its own sake. Moreover, an evolutionary perspective can disclose the instrumentality of art without destroying its unique value: '[...] it is more

8 For another kind of argument for avoiding a division of aesthetics and meaning of art see also (KIERAN 2005). 
plausible to explain the human possession of the capacity for aesthetic experience in terms of the advantages it affords vis-à-vis natural selection rather than in terms of valuation for its own sake.' (CARROLL 2000: 198) ${ }^{9}$ Those assertions are fully compatible with the theoretical cognitive basis. Furthermore, they make possible to establish the cognitive and phenomenal realm of aesthetics.

The amalgamated mind is the plausible instrument which can be used to explain the human perception of an artwork's form; and it can also explain its expression to a certain degree. For instance, with the help of neuroaesthetics we are able to better understand perception as the process of discarding ' $[. .$.$] inessential information from$ the visual world in order to represent the proper character of objects' (CINZIA and VITTORIO 2009: 682). Research in neuroscience has revealed '[... in brain] motor resonance congruent with the implied movements portrayed in the sculptures' (CINZIA and VITTORIO 2009: 683; see also FREEDBERG and GALLESE 2007). Recent research is also focused on the importance of empathy in the aesthetic experience. In a collaboration with structuralism or mathematical modelling there is an extensive space for exploring the formal aspects of artwork and the impact of form on our experience of art. Engaging the theoretical viewpoint of embodiment, scientists are ready to grasp new perspectives.

For me, as a phenomenologist, it is much more interesting to reach for the next level of understanding art. This cannot be achieved merely within the cognitive paradigm. To use Carroll's analysis of aesthetic experience again, there is a part of artistic expression that can be adequately described through first-person evidence. And, finally, there are many artworks which can possess a meaning. As shown earlier, interpretation is an instrument to negotiate our own life with others. From a philosophical perspective, this is a situation enabling us to open the existential dimension of art. It means that we should not deconstruct the meaning (as it is in semiotics), or merely describe the formal structure of the meaning, but we as the audience have to step into the meaning. In terms of hermeneutics, we have to be a part of constructing the meaning (GADAMER 1990: 116-26). ${ }^{10}$ This can only be done in the realm of phenomenality. And, of course, hermeneutics is also a kind of phronesis - an embodied cognition. ${ }^{11}$

Is the meaning of art really that important to the scholar of art? I think so, not only because it adequately corresponds to the human existential situation (the hermeneutics of Dasein $^{12}$ ), but also because there is a plethora of artwork which was intentionally created to provide readers or spectators insights into their own worlds. We also know

9 See also a vibrant attempt to re-evaluate art as a part of Lebenswelt (an instrument for making things special) from the evolutionary perspective in (DISSANAYAKE 1999).

10 The mimetic representation of artwork brings truth to being: 'Genauer kann man sagen: die mimische Darstellung der Aufführung bringt das zum Da-sein, was die Dichtung und ihrem Stoff und vom Dichtung und Aufführung entspricht eine doppelte Nichtunterscheidung als die Einheit der Wahrheit, die man in Spiel der Kunst erkennt.' (GADAMER 1990: 122)

11 See also (RESE 2007).

12 Heidegger explains the logos of any phenomenology of Dasein in the terms of hermeneutics, 'Phänomenologie des Daseins ist Hermeneutik...' (HEIDEGGER 1967: 37 [\$7 C]). 
that audiences often used to interpret artworks to improve their understanding of the human condition. There are morals we must attach to our understanding (to be able to enjoy the story), especially in the narrative forms of art (CARROLL 1996). From Odyssey and Divine Comedy, to Madame Bovary and The Ring of the Nibelung, there are a myriad of dramas, stories, poems, images and pieces of music which are intended to be interpreted; and indeed have been interpreted. Art historians have no excuse to constrain themselves only to third-person research on formal aspects of art. They should not preclude one whole part of both the historical and contemporary art world.

\section{Is Cognitive Phenomenology Possible?}

I have presented some key ideas about two important aspects of the amalgamated mind - practical wisdom and its existential implications (phenomenality). Now it is time to conclude in terms of a coherent theoretical and methodological approach. I use the notion of cognitive phenomenology for the description of the marriage between cognitive science (especially its embodied variant) and phenomenology (or first-person hermeneutical analysis $){ }^{13}$

Cognitive phenomenology is hardly a new concept; but the former definitions were more reserved, and provided only a limited utility for aesthetics and theatre studies. The minimal idea of cognitive phenomenology was recently presented as the reintroduction of first-person experience in cognitive research (see e.g. ROTH 2004). Phenomenology is, in that sense, used widely as just another term for the first-person method, posed as complementary to the traditional experimental third-person epistemology (surveillance, observations).

The problem of the marriage of those perspectives can be described as follows: '[...] the natural sciences assume the existence of a natural world independent from the observer. In contrast, in phenomenology this assumption is bracketed and its interest focuses on the structure of the experience as such.' (VALENZUELA-MOGUILLANSKY 2014: 108) The so-called hard problem - the question of a link between mind and consciousness - seems to be currently unsolvable.

As Francisco J. Varela (the founder of neurophenomenology) claims: both conscience (Ich, 'I', self) and mind (in our case, the amalgamated mind of cognitive approach) are irreducible (VARELA 1996). His theoretical concept seems to be one of the best elaborated, emphasizing the methodological rigidity of phenomenological reduction. In the noteworthy volume, Naturalizing Phenomenology, Roy, Petitot, Pachoud and Varela define the naturalization of phenomenology as a mutual constraint: neurological data (nota bene!). As such, mirror cortical neurons, efference copy or resonant cell assemblies are

13 The aim to connect cognitive science to other scientific fields is hardly new. For instance, there are notable endeavours to introduce cognitive science to social sciences (e.g. SUN 2012) or we can observe integrative efforts aiming to merge neurosciences in the particular field's framework (e.g. STAM 2015 or FELDMAN 2010). I do not conceive phenomenology as a scientific field. Rather I use the concept as an universal method utilizable in both humanities and science. 
mirrored by phenomenological data, such as intersubjective constitution, voluntary action or cognitive states. There is a 'wavy line problem' between them: the neurobiological and phenomenological are counterparts and they relate to each other through reciprocal constraints (ROY et al. 2000: 67). But the character of the reciprocity remains unsolved. Authors only discuss some possible solutions with the preference of generative passages $^{14}$ theory.

As argued earlier, there is no need to answer the question of how to connect the two detached perspectives (embodied mind/phenomenality). This issue is rooted in the delusive problem of the explanatory gap: the question of how to divorce the subjective experience from its objective physical nature (LUTZ 2004: 325). The problem vanishes when we realize that there is no need to ask this type of question. Let me explain with the help of wave-particle duality. ${ }^{15}$

As can be currently ascertained via physics, every beam of light behaves as a particle and has wave properties at the same time; light can thus be described as both particles and/or waves. Both possibilities are plausible (in certain conditions). As Albert Einstein and Leopold Infeld wrote in The Evolution of Physics: 'We have two contradictory pictures of reality; separately neither of them fully explains the phenomena of light, but together they do!' (EINSTEIN and INFELD 1966: 263)

This analogy is not really fair, because the hard problem poses the question - how is it possible to derive subjective experience? In the case of particles and waves there is no problem of separating one from another. But our quandary is similar in some respects: there are two (contradictory) pictures of reality, and each of them is irreducible. How can we work with them? I would like to propound that it can be managed in terms of pragmatism.

Pragmatism uses theories with respect to their satisfactory utility. If we wish to understand artwork in the terms of expression and meaning, we can successfully use phenomenology. If we wish to explain how meaning is constructed, and how it is that artwork produces certain emotions, the amalgamated mind and cognitive neuroscience can be useful instruments.

The sense of pragmatics is that we apply adequate theories to appropriate research questions. But we still understand that there is no way to completely comprehend artwork via just one of the two perspectives. The totality of art is only available if we apply both cognitive and phenomenological approaches. That is, if we use both firstperson evidence and third-person observation and analysis. Because I am not a psychologist and my intention is not to vindicate the materialistic assumption asserting that subjective consciousness has to be derived from objective physical nature (and I am even convinced that this question is of no purpose), I can lay the hard problem aside. I am focused on the artwork (i.e. particularly theatre performance), and it is useful to use both perspectives when studying a piece, according to my particular research question.

14 There is no space for explanation of the theory, see (ROY et al. 2000: 68).

15 This dualism is of another nature than the philosophical one. 
To conclude this section, I am going to use the notion cognitive phenomenology not in the sense of neurophenomenology ('naturalized' phenomenology) or as the manifestation of Cartesian dualism (which I have withheld), but as a kind of the two-dimensionality of the human mind; which provides me with the possibility to study the technique of an artwork (form, expression to some degree - 'the rules') - cognition of amalgamated mind, and/or to study the practical meaning of an artwork ('to step into the meaning') - phenomenality.

There is no need to put aside any of the two methodological approaches just because we are committed to the vision of one coherent theoretical and methodological paradigm. As Bruno Latour (1991) reveals in his book We Have Never Been Modern, the real delusion of modernity is the mythology of purified culture and nature. We are conversely immersed in hybridism, dwelling both in culture and nature. We can overcome the obstacles of modernity, if we are able to admit that our research has to start with the phenomenon. And, based on the phenomenon, we are ready to grasp culture or nature. But we need not to use the notions of nature or culture to explain (and destroy) the phenomenon. ${ }^{16}$ It is of no worth trying to destruct an artwork in order to use a methodologically rigid theory. The outcome of this type of research is meaningless.

\section{Cognitive Phenomenology in Theatre Studies}

How should cognitive phenomenology be used in theatre studies? Is there a method of integrating both phenomenology and cognitive science in art research? In her monograph, The Feeling Body ${ }^{17}$, Giovanna Colombetti deals with the issue of reconciling both neuroscientific and phenomenological approaches. According to her interpretation of Varela's neurophenomenological project, first-person data should be collected '[...] to shed light on, or interpret, physical activity, whereas third-person data should in turn be used to guide experiental reports and to help subjects discover and report on previously unnoted aspects of their experience' (COLOMBETTI 2014: 136). She presents her own methodology, which is based on the following steps:

1. Self-observation (first-person methods)

2. Intersubjective validation (second-person methods)

3. Recording brain and bodily activity (third-person methods)

4. Correlating first- and third-person data

5. Use of third-person methods to refine self-observation

(COLOMBETTI 2014: 148-63)

From the perspective of this article, Colombetti's conception is too narrow. She aims to provide instruments for research on human emotions and experiences, but I am

16 For more precise elaboration of this argument see (LATOUR 1991).

17 I am indebted to my reviewer who has brought this book to my attention. 
headed towards a more holistic approach. She hardly grants a sufficient significance to artwork. Her method is useful for interpreting and explaining audience experience and the process of acting, but it is not utilizable for the analysis of perceived artwork. With this approach we are at risk of having the artwork be forgotten. As explained earlier, we have to avoid research on the meaning of art (phenomenological hermeneutics) being omitted. The meaning of an artwork adequately corresponds to the human existential situation. Phenomenological hermeneutics attempts to understand the human condition (hermeneutics of Dasein) and is inevitable to retain an artwork's totality. Theatre studies should not reduce itself to the mere psychology of performance. However, there is no need for the restoration of structuralist debiologization. We have to avoid both psychological and formalistic reduction.

I suggest the following steps:

1. Enrich the prevailing sheer formalistic methods with the embodied approach (the concept of amalgamated mind being pertinent framework)

2. Deepen the research on both audience and actors, using both first- and third-person methods of inquiry (neurophenomenology)

3. Integrate phenomenological hermeneutics (first-person interpretation by researcher) into the analysis of artwork, preserving the value of its testimony to the existential situation of human.

Since the marriage of phenomenology and cognitive science in the realm of art should not to be pragmatic, it has to start with courting. Both sides of the 'barricade' (first- and third-person methods) have to be open and begin a dialogue. Promoting collaboration of philosophers, psychologists, theatre historians and linguists is a valuable first step. Mixed teams of researchers can share their experiences productively. This integrative approach hardly means uniformity. On the contrary, it is advisable to preserve the methodological and theoretical diversity and provide the plurality of explanations and interpretations. As in any partnership, outcomes will be enriched with shared experience. There is hardly ever just uniformity or just isolationist pluralism (GIJSBERS 2016). Scholars in theatre studies can flourish only if they integrate methodological differences in a collaborative effort. ${ }^{18}$

\section{Concluding Remarks}

The cognitive approach is new for Czech theatre theory and the Czech scholars who have explored its possibilities so far (e.g. HAVLÍČKOVÁ KYSOVÁ 2015). My intention was not to substitute a necessary in-depth discussion about cognitive theatre studies in Czech context. I am more interested in phenomenology than in cognitive science. But the present project of cognitive phenomenology I understand as a promising way for

18 I deliberately omit the field of artistic research. This article is not suitable for discussing this engrossing issue. See the example of merging cognitive approach in artistic research in (REPAŠSKÁ 2015). 
a collaboration of scientists and art scholars. The aforementioned two-dimensionality of mind (its phenomenality/existentiality and physiology) is not an obstacle, but an invitation to cooperate. I envision both experimentally and interpretatively oriented research teams from both fields of science and humanities, trying not only to explain theatre and artworks, but also to understand them in their existential dimension. Hopefully, my theoretical contribution can be used as the groundwork for future elaboration, especially from a methodological perspective for research.

\section{Bibliography}

AQUINAS, Thomas. 1880. S. Thomae Aquinatis Summa Theologica: Tomus secundus [St. Thomas Aquinas Summa Theologica. The Second Book]. Paris: Bloud \& Barral, 1880.

ARISTOTLE. 2011. Nicomachean Ethics. Chicago/London: The University of Chicago Press, 2011.

BACHELARD, Gaston. 1968. Le nouvel esprit scientifique [The New Scientific Spirit]. Paris: Presses universitaires de France, 1968.

BANDURA, Albert. 1977. Social Learning Theory. New-Jersey: Prentice-Hall, 1977.

BRETON, Philippe. 1997. L'utopie de la communication [The Utopia of Communication]. Paris: La Découverte, 1997.

BRETON, Philippe. 2011. La sacralisation de l'information. ESSACHESS: Journal for Communication Studies 4 (2011): 2: 59-67.

CARROLL, Noël. 1996. Moderate Moralism. British Journal of Aesthetics 36 (1996): 3: 223-38.

CARROLL, Noël. 2000. Art and the Domain of the Aesthetic. British Journal of Aesthetics 40 (2000): 191-208.

COLOMBETTI, Giovanna. 2014. The Feeling Body: Affective Science Meets the Enactive Mind. Cambridge, MA: The MIT Press, 2014.

DELAMER, John and Amanad WARD (eds.). 2013. Handbook of Social Psychology. Dordrecht: Springer, 2013.

DI DIO, Cinzia and Vittorio GALLESE. 2009. Neuroaesthetics: a review. Current Opinion in Neurobiology 19 (2009): 6: 682-7. DOI: 10.1016/j.conb.2009.09.001.

DISSANAYAKE, Ellen. 1999. Homo Aestheticus: Where Art Comes From and Why. Seattle/London: University of Washington Press, 1999.

EINSTEIN, Albert and Leopold INFELD. 1966. The Evolution of Physics: From Early Concepts to Relativity and Quanta. New York: Touchstone, 1966.

FAIRCLOUGH, Norman. 1995. Critical Discourse Analysis: the Critical Study of Language. London/ New York: Longman, 1995.

FELDMAN, Jerome A. 2010. Cognitive Science Should Be Unified: Comments on Griffiths et al. and McClelland et al. Trends in Cognitive Sciences 14 (2010): 341. DOI: 10.1016/j. tics.2010.05.008.

FICHTE, J. G. 2000. Foundations of Natural Right: According the the Principles of the Wissenschaftslehre. Ed. by F. Neuhouser. Cambridge: Cambridge University Press, 2000. 
FINNIGAN, Bronwyn. 2014. Phronesis in Aristotle: Reconciling Deliberation with Spontaneity. Philosophy and Phenomenological Research (19 JUN 2014). DOI: 10.1111/phpr.12126.

FISKE, John and John HARTLEY. 2003. Reading Television. London/New York: Routledge, 2003.

FREEDBERG, David and Vittorio GALLESE. 2007. Motion, emotion and empathy in esthetic experience. Trends in Cognitive Sciences 11 (2007): 5: 197-203. DOI 10.1016/j.tics.2007.02.003.

GADAMER, Hans-Georg. 1990. Gesammelte Werke 1: Hermeneutik I: Wahrheit und Methode: Grundzüge einer philosophischen Hermeneutik [Truth and Method]. Tübingen: J. C. B. Mohr, 1990.

GIJSBERS, Victor. 2016. Explanatory Pluralism and the (Dis)Unity of Science: The Argument from Incompatible Counterfactual Consequences. Frontiers in Psychiatry 7 (2016): 32. DOI: 10.3389/fpsyt.2016.00032.

HAVLÍČKOVÁ KYSOVÁ, Šárka. 2015. Metafory, kterými hrajeme. Perspektivy a meze české kognitivní teatrologie [Metaphors We Act by. Perspectives and Challenges of Czech Cognitive Theatre Studies]. Theatralia 18 (2015): 1: 64-84.

HEGEL, Georg Wilhelm Friedrich. 2013. Grundlinien der Philosophie des Rechts. Berlin: Michael Holzinger, 2013.

HEIDEGGER, Martin. 1967. Sein und Zeit [Being and Time]. Tübingen: Max Niemeyer Verlag, 1967.

HUSSERL, Edmund. 1976. Die Krisis der europäischen Wissenschaften und die transzendentale Phänomenologie: Eine Einleitung in die phänomenologische Philosophie [The Crisis of European Sciences and Transcendental Phenomenology: An Introduction to Phenomenological Philosophy]. Haag: Martinus Nijhoff, 1976.

JANKO, Richard. 1992. From Catharsis to the Aristotelian Mean. In Amélie Oksenberg Rorty (ed.). Essays on Aristotle's Poetics. Princeton: Princeton University Press, 1992: 341-58.

KIERAN, Matthew. 2005. Revealing Art. New York: Routledge, 2005.

LATOUR, Bruno. 1991. Nous n'avons jamais été modernes: Essai d'anthropologie symétrique. [We Have Never Been Modern] Paris: La Découverte, 1991.

LUTZ, Antoine. 2004. Introduction - the explanatory gap: To close or to bridge? Phenomenology and the Cognitive Sciences 3 (2004): 325-30.

MASSEY, Irving. 2009. The Neural Imagination: Aesthetic and Neuroscientific Approaches to the Arts. Austin: University of Texas Press, 2009.

NEISSER, Ulric. 2014. Cognitive Psychology: Classic Edition. New York/London: Psychology Press, 2014.

REPAŠSKÁ, Lucia. 2015. Dekompozičné princípy v inscenačnej tvorbe [Decomposition in Stage Practice]. Brno: JAMU, 2015.

RESE, Friederike. 2007. Phronesis als Modell der Hermeneutik: Die hermeneutische Aktualität des Aristoteles (GW1, 312-29) [Phronesis as Hermeneutic Model: Aristotle's Hermenautic Aktuality]. In Günter Figal (ed.). Hans-Georg Gadamer: Warheit und Methode. Berlin: Akademie Verlag, 2007: 127-49.

ROTH, Wolff-Michael. 2004. Cognitive Phenomenology: Marriage of Phenomenology and Cognitive Science. Forum: Qualitative Social Research 5 (2004): 3.

ROWLANDS, Mark. 2010. The New Science of the Mind. Cambridge, MA: MIT, 2010. 
ROY, Jean-Michel et al. 2000. Beyond the Gap: An Introduction to Naturalizing Phenomenology. In Jean Petitot et al. Naturalizing Phenomenology: Issues in Contemporary Phenomenology and Cognitive Science. Stanford: Stanford University Press, 2000: 1-80.

SEARLE, John R. 1980. Minds, Brains, and Programs. The Behavioral and Brain Sciences 3 (1980): 417-57.

SIEGEL, Jerrold. 2005. The Idea of the Self: Thought and Experience in Western Europe since the Seventeenth Century. Cambridge: Cambridge University Press, 2005.

STAM, Henderikus J. 2015. The Neurosciences and the Search for a Unified Psychology: the Science and Esthetics of a Single Framework. Frontiers in Psychology 6 (2015): 1-9. DOI: 10.3389/ fpsyg.2015.01467.

STERNBERG, Robert J. 2009. Cognitive Psychology. Belmont: Wadsworth, 2009.

SUN, Ron (ed.). 2012. Grounding Social Sciences in Cognitive Sciences. Cambridge, MA: The MIT Press, 2012.

VALENZUELA-MOGUILLANSKY, Camila. 2014. Constructivist Foundations 10 (2014): 1: 108-9.

VARELA, Francisco J. 1996. Neurophenomenology: A Methodological Remedy for the Hard Problem. Journal of Consciousness Studies 3 (1996): 4: 330-49.

WEGNER, Daniel M. 2002. The Illusion of Conscious Will. Cambridge, MA: MIT Press, 2002.

WILSON, Margaret. 2002. Six Views of Embodied Cognition. Psychonomic Bulletin E Review 9 (2002): 4: 625-36.

ZAGZEBSKI, Linda Trinkaus. 1996. Virtues of the Mind: An Inquiry into the Nature of Virtue and the Ethical Foundations of Knowledge. Cambridge: Cambridge University Press, 1996. 


\section{Summary}

\section{Cognitive Phenomenology: the Promising Pragmatic Marriage of Methodologies in the Field of Theatre Studies?}

The article presents cognitive phenomenology as a new methodological possibility for the humanities, and especially theatre studies, avoiding communication theory reductionism. The author adapts the perspective of amalgamated mind (ROWLANDS 2010), and elaborates its usefulness for the study of art. The article also interprets Aristotle's practical wisdom as a concept fully compatible with the cognitive perspective, and shows that the cognitive perspective should not be contradictory to the phenomenological one. The relation of phenomenality to the amalgamated mind is also discussed. The author concludes that the 'marriage of methodologies' will be successful, but only if the irreducible natures of phenomenality and embodied mind are preserved.

\section{Keywords}

cognitive science, neuroaesthetics, phenomenology, hermeneutics, theatre, artwork, methodology, humanities, hard problem

DOI: $10.5817 / T Y 2016-2-3$

\section{Jan Motal, Ph.D.}

Janáček Academy of Music and Performing Arts and Masaryk University, Brno, Czech Republic E-mail: motal@jamu.cz

Jan Motal is a researcher at the Unit of Research into Theatre and Drama, Janáček Academy of Music and Performing Arts, and an assistant professor at the Faculty of Social Studies, Masaryk University. In his research he focuses on phenomenology and hermeneutics of art, religiosity in media and media ethics. 